\title{
Ecological Consequences of the Chernobyl Nuclear Accident
}

On the occasion of the first session of the Senior Advisers to the Economic Commission for Europe (ECE) Governments on Environmental and Water Problems, the Deputy Chairman of the USSR State Committee for Hydrometeorology, V.G. Sokolovsky, presented a report on the ecological consequences following the nuclear accident at Chernobyl on 26 April 1986. The situation had been characterized by complicated dynamics of emissions from the source, the formation of radioactive traces, and water pollution. He also explained the results of the studies that had been conducted during 1986-87 on the radiation impact on flora and fauna in the region of the accident.

According to the Soviet expert, one of the main problems in liquidating the consequences of the accident during the early weeks and months had been to protect the population from external radiation and consumption of contaminated local foodstuffs. During the first days after the accident, both the population and cattle were evacuated from the $30-\mathrm{km}$ zone around the site. Later, priority was given to the assessment and projection of the contamination of agricultural produce in adjacent areas, and, in a more generalized form, the assessment and projection of ecological consequences of environmental pollution in natural and agricultural ecosystems.

\section{Main Studies}

To such ends, studies were undertaken to measure radiation parameters on contaminated surfaces, including surface waters; on migration into the soil layer of the most dangerous (long-lived) radionuclides, their solubility and accessibility for root consumption under different soil and geographical conditions; on the initial airborne contamination of natural and agricultural vegetation, in order to decide on the possible use of local crops; and on dangerous radionuclides' accumulation in milk and the organs of domestic animals, in order to decide on the possible use of their meat. An assessment was also made of any direct and long-term (genetic) impact of radioactive contamination on the functional and structural parameters of natural ecosystems (mainly forests) and fauna.

The studies could partly lean on experience of contamination of the environment with radioactive products emitted into the atmosphere as a result of nuclear tests in the $1940 \mathrm{~s}-1960 \mathrm{~s}$, and also as a result of earlier accidents at nuclear-power installations. Large-scale and systematic surveys of ecological consequences of radioactive contamination of the environment were carried out during the first weeks after the Chernobyl accident in the areas adjacent to the power-plant site.

\section{- and Conclusions}

The broad scientific analysis of the accident and its consequences led to the following main conclusions: effects of direct radiation impact on plant and animal communities in the form of radiation damage to coniferous forests, and noticeable changes in the number of soil meso- and microfauna, were manifested in a limited zone of high radioactive contamination at a distance of several kilometres from the site of the accident.

Ecological effects of radioactive contamination itself have not been observed in the rest of the territory that was exposed to radioactive emission resulting from the accident. The consequences, for natural and agricultural ecosystems, of radioactive contamination of the terrain and ground-waters, are mainly caused by the transfer of radionuclides along the trophic 'soil-plant-animal' chain.

\section{Countermeasures Implemented}

The regularities of redistribution of radionuclides in natural and agro-systems, derived as a result of implementing a large-scale programme of radioecological surveys, made possible the development of basic principles of agricultural production in the contaminated territory. The following measures have been implemented:

- reorientation of farms in keeping up with the levels of land contamination; withdrawal of foodstuffs from direct consumption by humans; raising of crops for seeds and fodder;

- long-term fixation of radionuclides in a form inaccessible to plants by incorporating large doses of mineral fertilizers, lime, and sorbents (clay suspension, zeolites) into the upper contaminated soil-layer, with subsequent ploughing-in;

- radical improvement of natural meadows and expansion of territories sown with perennial grasses, which provides for a radical reduction of the content of radionuclides in fodder and beef; and

- pre-slaughter feeding of animals (45-60 days) with fodder free from radionuclides, so that beef could be used for consumption.

This complex of measures has allowed a stable functioning of agricultural production in the contaminated territory and, in this way, for minimizing the level of dose-loadings caused by feedstuffs.

UN ECONOMIC COMMISSION FOR EUROPE Palais des Nations 1211 Geneva 10 Switzerland.

\section{The World's Largest Flowers and Their Future*}

Two of the 13 known species of Rafflesia grow in Kinabalu Park in Sabah, Malaysia $-R$. pricei (Fig. 1) and $R$. keithii (Willem Meijer, pers. comm.). Their buds take up to nine months to mature and, upon blossoming, they smell faintly like carrion. This attracts flies and beetles, which may pollinate the flowers. Rafflesia arnoldii, a species incorrectly reported in Kinabalu Park in an earlier article (Conservation Education Programmes: Evaluate and Improve Them, Environmental Conservation, 14(3), pp. 201-

\footnotetext{
* See also Pollination of Rafflesia (Rafflesiaceae), in American Journal of Botany, 75(8), pp. 1148-67, 10 figs, 1988, by Reed S. Beaman, Pamela J. Decker \& John H. Beaman.-Ed.
}

$6,1987)$, is perhaps the showiest of the species, but grows only in Sumatra. It was first described by its European discoverers as 'the greatest prodigy of the vegetable world.' Upon finding a blossom weighing $7 \mathrm{~kg}$, Sir Stamford Raffles, explorer and founder of Singapore, declared it to be 'the most magnificent flower in the world.' With a diameter of about one metre (Botanist Dr Willem Meijer recently measured a blossom $91 \mathrm{~cm}$ in diameter and noted an unofficial record of $1.07 \mathrm{~m})$, Rafflesia arnoldii is the world's largest flower.

Rafflesia flowers are rare as well as enormous, the entire genus and family being restricted to the tropical forests of Southeast Asia. Their tiny seeds infect the trailing stems of wild grape-vines (such as Tetrastigma spp.). Rafflesia 